\title{
A local validation of the APLS pediatric age-based weight estimation formula
}

\begin{abstract}
Objective: Authors aimed to check the accuracy of the Advanced Pediatric Life Support (APLS) pediatric weight estimation formula (Weight in $\mathrm{kg}=($ Age in year +4$) \times 2)$ in Mali. This formula has been proposed for weight estimation if direct measurement is not available, but its accuracy has been discussed in some studies.
\end{abstract}

Method: It was a retrospective analysis of anesthetic files. Collected data were age, gender, the ASA status, actual weight and estimated weight. Statistical analysis was performed with SPSS 20, using the Wilcoxon test and Spearman coefficient.

Results: Seven hundred and twenty four children were included, with a mean age of 71 , $07 \pm 47,98$ months. Mean measured weight was $20,09 \pm 8,56 \mathrm{~kg}$ versus $19.85 \pm 7.99 \mathrm{~kg}$ for the formula based estimated weight $(\mathrm{p}<0.001)$. Actual weight were concordant with estimated one in $61,46 \%$ of cases. The estimate error was $13.86 \%$ to $40.34 \%$ of measured weight in the 1 to 10 years old children, while it was from -11 to $+15 \mathrm{~kg}$ in children over 10 years old.

Conclusion: The APLS formula was accurate in $61,46 \%$, and seems to be applicable for 1 to 10 years old children.

Keywords: accuracy, APLS, formula, pediatric weigh
Volume 8 Issue 5 - 2017

\author{
Joseph Koné,' Mamadou Karim Touré,' \\ Ramatoulaye Diamouténé, I Emmanuel \\ Traoré,' Diénéba Doumbia, ${ }^{2}$ Yakaria \\ Coulibaly, ${ }^{3}$ Mamadou Traoréé \\ 'Department of Anesthesia, Resuscitation, Woman Mother Child \\ Hospital, Mali \\ ${ }^{2}$ Department of Anesthesia, Resuscitation, Point G University \\ Hospital, Mali \\ ${ }^{3}$ Pediatric Surgery Department of Gabriel Touré University \\ Hospital, Mali \\ ${ }^{4}$ URFOSAME (Health research and training unit mother and \\ child/Research and Training Center in Mother and Child health), \\ Mali
}

Correspondence: Joseph Koné, Department of AnesthesiaResuscitation, Hospital, Mother-Child, Bamako, Mali, Tel 00223 667664 26, Email drjosephkone@yahoo.fr

Received: September 20, 2017 | Published: September 25 2017
Abbreviations: APLS, advanced pediatric life support; ASA, American society of anesthesiologist; WHO, World Health Organization; SPSS, statistical package for social sciences

\section{Introduction}

Introduction should provide background, comprehensive insight on the purpose of the study and its significance. Weight is one of the first anthropometric parameter measured in the new-born. ${ }^{1}$ In emergency, resuscitation and anesthesiology, it is widely used for many decisions such as drug and fluid dose calculation.

In emergency contexts, it's often impossible to have exact weight by scale measurement due to patient clinical status (unconsciousness, severe burn or trauma, risk of pain exacerbation, agitation) or the absence of calibrated scales. Most of weigh estimation methods haven't been developed on sub-saharan child growth and nutritional standards, and need to be validated and adapted in those populations. To be efficient and to prevent drugs doses related medical errors, anesthetists need the most accurate method for child's weight estimation. ${ }^{2}$ Several methods have been proposed based on age, length-weight relationships, foot or mid-arm size, clinician experience or parent estimate..$^{3-10}$

We focused this study on the APLS age-based weight estimation formula "weight $=($ age +4$) \times 2$ ", to check its performance for weight calculation in malian children attending anesthetic evaluation. According to some disparities in studies results in different regional, nutritional or ethnic groups, it's essential to establish its adequacy in local conditions. ${ }^{10,11}$ The main objective of this study was to evaluate the formula in 01 to 15 years old children.

\section{Materials and methods}

This was a retrospective analysis of anesthetic files in pediatric patients who have attended the anesthetic evaluation in the Mère-
Enfant "le Luxembourg" hospital in Bamako (Mali). We enrolled the files of ASA I or II stable children, aged from to 1 to 15 years with a normal proportion on the WHO weight-for-age child growth charts. Children with a story of weight loss where not included, as those whom the exact weight was not clearly notified on medical file. Data collected were age (in months), gender, the ASA status, actual weight (to the nearest kilogram) and estimated weight. Children were weighed with a standing scale. When the child couldn't stay alone for measurement, its weight was determined by indirect weighting using an accompanying person.

We calculated first the strictly agreement between the child actual weight and the one predicted by the formulae, and focused our analysis on the difference, in percentage and absolute value. Secondary we assessed the performance proportion of the formula in an agreement within $10 \%$ of actual weight. Statistical analysis was performed by using SPSS programs, with Wilcoxon test and Spearman coefficient for correlation between age and estimation error. Data were presented as numbers (percentages), means with standards deviations, and ap value of $<0.05$ considered as indicator of statistical significance.

\section{Results and discussion}

Seven hundred and twenty four (724) children were enrolled in this study. There were 460 boys $(63.5 \%)$ and 264 girls (36.5\%). The mean measured weight was $20.10 \pm 8.62 \mathrm{~kg}$ in comparison with an estimation predicted weight of $19.85 \pm 7.99 \mathrm{~kg}(\mathrm{p}<0,0001)$ (Table 1). Formula based weight estimate was exact in $61.46 \%$ (Figure 1). Error range was from -11 to $+15 \mathrm{~kg}$ from measured weight (Figure 2). The mean differences between measured weight and calculated weight was 3 , $23 \pm 2,82 \mathrm{~kg}$ sur $(\mathrm{n}=724)$. It was up to $5,72 \pm 3,49 \mathrm{~kg}$ in range 4 ( 10 to 15 years old children) (Table 2). We have observed that the error absolute value was proportional to age range with a significant correlation of age with estimation absolute value $(r=0.581 ; p=0.001)$ (Figure 3$)$. 
Table I Demographic and clinical characteristics

\begin{tabular}{ll} 
Demographics & Values \\
\hline $\begin{array}{l}\text { Age (in months) } \\
\text { Age ranges }\end{array}$ & $71.07 \pm 47.98$ \\
I: [I2 to 24 months] & $165(22.8 \%)$ \\
2: [25 to 60 months] & $234(32.3 \%)$ \\
4: [6I to I 20 months] & $204(28.2 \%)$ \\
5: [over I 20 months] & $121(16.7 \%)$ \\
Gender & \\
Male & $460(63.5 \%)$ \\
Female & $264(36.5 \%)$ \\
Weights (in Kg) & \\
Measured weight & $20.09 \pm 8.56$ \\
Formula based estimate & $19.85 \pm 7.99$ \\
\hline
\end{tabular}

Table 2 Mean differences between measured weight and calculated weight (in kilograms)

\begin{tabular}{llllll}
\hline $\begin{array}{l}\text { Age } \\
\text { range }\end{array}$ & $\begin{array}{l}\text { Measured } \\
\text { weight }\end{array}$ & $\begin{array}{l}\text { Calculated } \\
\text { weight }\end{array}$ & p value & $\begin{array}{l}\text { Estimation } \\
\text { error }\end{array}$ & $\begin{array}{l}\text { Error } \\
\text { range }\end{array}$ \\
\hline$(\mathrm{N}=724)$ & $20.09 \pm 8.564$ & $19.85 \pm 7.997$ & $<0.001$ & $3.23 \pm 2.82$ & {$[1-15]$} \\
$1(\mathrm{n}=165)$ & $11.70 \pm 1.327$ & $11.26 \pm 0.805$ & $<0.001$ & $1.61 \pm 0.98$ & {$[1-4]$} \\
$2(\mathrm{n}=234)$ & $15.53 \pm 2.534$ & $15.52 \pm 1.725$ & $<0.001$ & $2.12 \pm 1.59$ & {$[1-9]$} \\
$3(\mathrm{n}=204)$ & $23.32 \pm 3.455$ & $23.44 \pm 2.689$ & $<0.001$ & $3.08 \pm 1.98$ & {$[1-9]$} \\
$4(=121)$ & $34.89 \pm 5.560$ & $33.87 \pm 2.869$ & $<0.001$ & $5.72 \pm 3.49$ & {$[1-15]$} \\
\hline
\end{tabular}

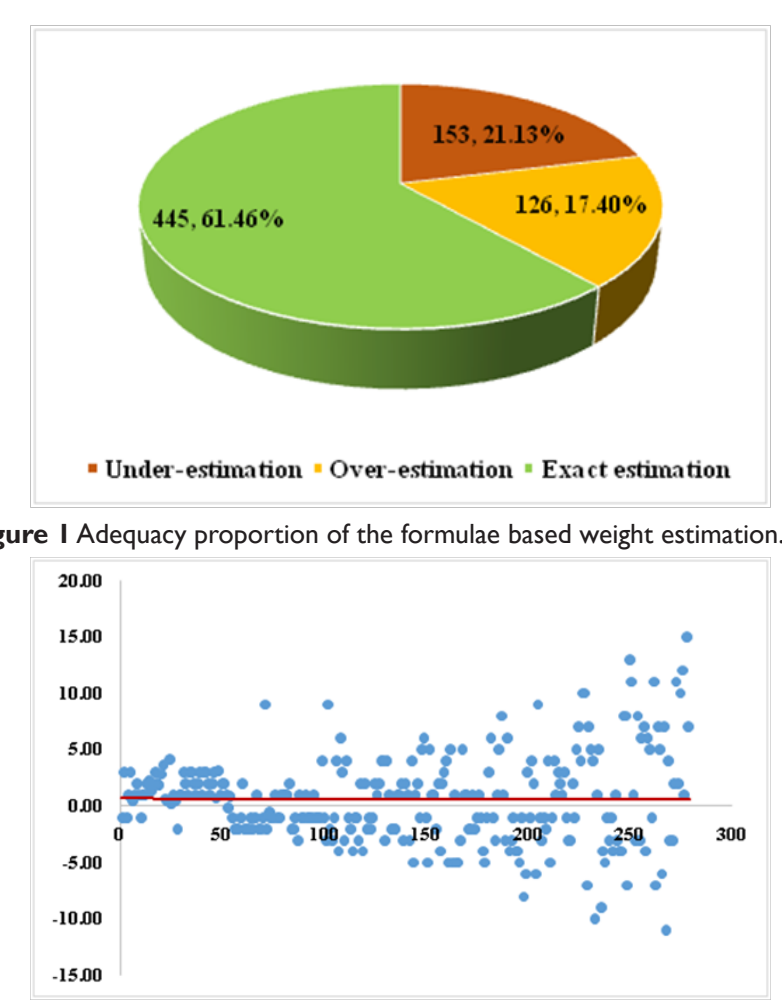

Figure 2 Dispersion graphic of estimation error from the actual weight (in red baseline).

\section{Discussion}

Many weight estimation formulas and methods have been developed for clinical use when measurement is not possible. ${ }^{12}$ They have been also evaluated by several validation studies, but there are a large proportion of disparities in results regarding geographical and nutritional considerations in the estimation performance. The accuracy of formulas is not perfect, and they should be used only in absence of exact weight measurement. This study will highlight the limits of the APLS worldwide used formulae in subsaharan populations.

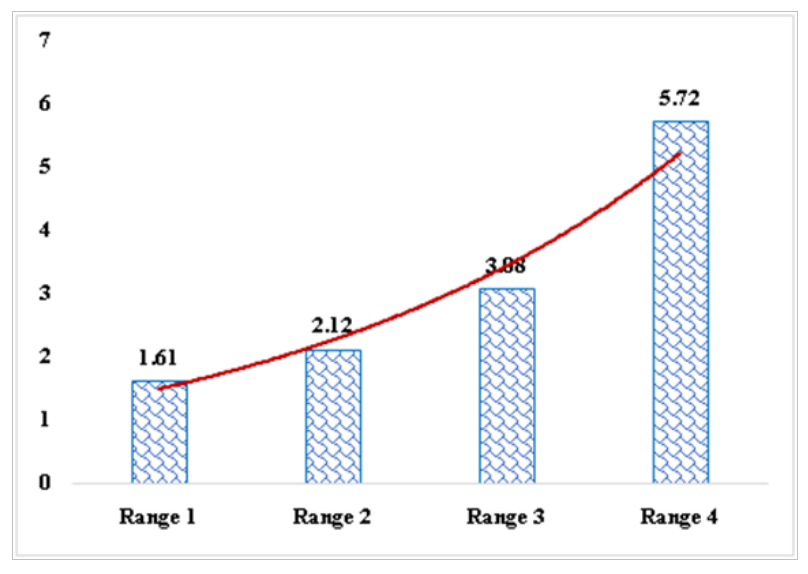

Figure 3 Absolute values of mean estimation errors by age ranges.

Calibrated scales are used for direct weighting in clinical practice. In our study, 724 files have been screened in boys and girls who attended anesthetic evaluation for minor surgery. They were from ASA 1 and 2, without any evident condition which would affect their weight. The APLS formula $[$ Weight $=($ Age +4$) \times 2]$ performed an exact estimate in $61,46 \%$, with a statistical difference between under or overestimate [underestimate in $21,13 \%$ versus overestimate in 17 , $40 \% ; \mathrm{p}<0.001]$ (Figure 1). Differences between actual weight and calculated weight (estimation error) were from $-11 \mathrm{~kg}$ to $+15 \mathrm{~kg}$. We observed an absolute values of estimating error of about $1.61 \pm 0.98 \mathrm{~kg}$ in age range 1 (12 to 24 months), $2.12 \pm 1.59 \mathrm{~kg}$ in age range 2 ( 25 to 60 months), $3,08 \pm 1.98 \mathrm{~kg}$ in age range 3 (61 to 120 months) and $5.72 \pm 3,49 \mathrm{~kg}$ in age range 4 (over 120 months), (Figure 2). This difference was age proportional, with a linear positive correlation $(\mathrm{r}=0.581 ; \mathrm{p}<0.001)$. Calculating the percentage of estimation-error from the measured weight, the median of estimation-error (absolute value) was $15 \%$ with $8,57 \%$ and $34 \%$ as first and third quartiles. This error percentage was less than $13,68 \%$ in age ranges 1 and 2 , while it was up to $40,43 \%$ in age range 4 with high extreme of $+15 \mathrm{~kg}$. This may lead to reasonable drug management technicity in over 10 years old children. By simulation, a 14 years old child with $25 \mathrm{~kg}$ should weight $36 \mathrm{~kg}$ on this age-based weight calculation; Consequently he might have $144 \mathrm{mg}$ of ketamine $(6.48 \mathrm{mg} / \mathrm{kg}$ versus maximal recommended IV dose of $4.5 \mathrm{mg} / \mathrm{kg}$ ) in an emergency condition. This difference was age proportional, with a linear positive correlation $(\mathrm{r}=0.581$; $\mathrm{p}<0.001$ ). Calculating the percentage of estimation-error from the measured weight, the median of estimation-error (absolute value) was $15 \%$ with $8,57 \%$ and $34 \%$ as first and third quartiles. This error percentage was less than $13,68 \%$ in age ranges 1 and 2 , while it was up to $40,43 \%$ in age range 4 with high extreme of $+15 \mathrm{~kg}$. This may lead to reasonable drug management technicity in over 10 years old children. By simulation, a 14 years old child with $25 \mathrm{~kg}$ should weight $36 \mathrm{~kg}$ on this age-based weight calculation; Consequently he might have $144 \mathrm{mg}$ of ketamine $(6.48 \mathrm{mg} / \mathrm{kg}$ versus maximal recommended IV dose of $4.5 \mathrm{mg} / \mathrm{kg}$ ) in an emergency condition. This difference was age proportional, with a linear positive correlation $(\mathrm{r}=0.581$; $\mathrm{p}<0.001$ ). Calculating the percentage of estimation-error from the measured weight, the median of estimation-error (absolute value) was $15 \%$ with $8,57 \%$ and $34 \%$ as first and third quartiles. This error percentage was less than $13,68 \%$ in age ranges 1 and 2, while it was up to $40,43 \%$ in age range 4 with high extreme of $+15 \mathrm{~kg}$. This may 
lead to reasonable drug management technicity in over 10 years old children. By simulation, a 14 years old child with $25 \mathrm{~kg}$ should weight $36 \mathrm{~kg}$ on this age-based weight calculation; Consequently he might have $144 \mathrm{mg}$ of ketamine $(6.48 \mathrm{mg} / \mathrm{kg}$ versus maximal recommended IV dose of $4.5 \mathrm{mg} / \mathrm{kg}$ ) in an emergency condition. Calculating the percentage of estimation-error from the measured weight, the median of estimation-error (absolute value) was $15 \%$ with $8,57 \%$ and $34 \%$ as first and third quartiles. This error percentage was less than 13 , $68 \%$ in age ranges 1 and 2, while it was up to $40,43 \%$ in age range 4 with high extreme of $+15 \mathrm{~kg}$. This may lead to reasonable drug management technicity in over 10 years old children. By simulation, a 14 years old child with $25 \mathrm{~kg}$ should weight $36 \mathrm{~kg}$ on this age-based weight calculation; Consequently he might have $144 \mathrm{mg}$ of ketamine $(6.48 \mathrm{mg} / \mathrm{kg}$ versus maximal recommended IV dose of $4.5 \mathrm{mg} / \mathrm{kg})$ in an emergency condition. Calculating the percentage of estimation-error from the measured weight, the median of estimation-error (absolute value) was $15 \%$ with $8,57 \%$ and $34 \%$ as first and third quartiles. This error percentage was less than $13,68 \%$ in age ranges 1 and 2, while it was up to $40,43 \%$ in age range 4 with high extreme of $+15 \mathrm{~kg}$. This may lead to reasonable drug management technicity in over 10 years old children. By simulation, a 14 years old child with $25 \mathrm{~kg}$ should weight $36 \mathrm{~kg}$ on this age-based weight calculation; Consequently he might have $144 \mathrm{mg}$ of ketamine $(6.48 \mathrm{mg} / \mathrm{kg}$ versus maximal recommended IV dose of $4.5 \mathrm{mg} / \mathrm{kg}$ ) in an emergency condition. While it was up to $40,43 \%$ in age range 4 with high extreme of $+15 \mathrm{~kg}$. This may lead to reasonable drug management technicity in over 10 years old children. By simulation, a 14 years old child with $25 \mathrm{~kg}$ should weight $36 \mathrm{~kg}$ on this age-based weight calculation; Consequently he might have $144 \mathrm{mg}$ of ketamine $(6.48 \mathrm{mg} / \mathrm{kg}$ versus maximal recommended IV dose of $4.5 \mathrm{mg} / \mathrm{kg}$ ) in an emergency condition. While it was up to $40,43 \%$ in age range 4 with high extreme of $+15 \mathrm{~kg}$. This may lead to reasonable drug management technicity in over 10 years old children. By simulation, a 14 years old child with $25 \mathrm{~kg}$ should weight $36 \mathrm{~kg}$ on this age-based weight calculation; consequently he might have $144 \mathrm{mg}$ of ketamine $(6.48 \mathrm{mg} / \mathrm{kg}$ versus maximal recommended IV dose of $4.5 \mathrm{mg} / \mathrm{kg}$ ) in an emergency condition.

In the UK, the formula has been evaluated to underestimate children's weights in about $33.4 \%$ over the age range 1 to 16 years. Several formulas have been derivate from this classical one, like the formula "Weight $=($ age x 3$)+7$ ". In 2011, APLS course has proposed another weight estimation method based on three ageranges: (age in months $\times 0,5)+4$ for children aged 1-12 months, $(2 \times$ age in years $)+8$ for children aged $1-5$ years and $(3 \times$ age in years $)+7$ for children aged 6-12 years. ${ }^{13}$ It might be more adequate, but looks to be not easy to remember and use in emergency settings. ${ }^{14}$ Tinning and al. in Australia have proposed three linear equations to estimate pediatric weight, presented as: for infants $<12$ months: Weight $(\mathrm{kg})$ $=($ age in months +9$) / 2$; for children aged 1-5years: Weight $(\mathrm{kg})=$ $($ age in years +5$) \times 2$; for children aged 5-14 years: Weight $=$ age in years $\mathrm{x} 4$. This formula may be more accurate than the APLS classical formula. ${ }^{8}$ In comparison with several weight prediction methods, Krieser and al found parent estimation more accurate than several methods. ${ }^{7}$ This may consider the parent ability to know and give his child weight.

In our study, the formula has shown a statistically identical performance in both sex groups (36.4\% in boys versus $38.5 \%$ in girls; $\mathrm{p}=0.572$ ). Gender impact on age-based weight estimation formula is not well documented in published studies. Research results are so divergent on the APLS formula, depending on studies designs and on geographic, demographic, and others conditions. Our study has some limitations like retrospective design in patients screened on the inclusion base of WHO standard weight for age charts. The Impact of weighting errors on medical outcomes might be assessed in further surveys.

\section{Conclusion}

Methods estimating children's weight should not be acceptable when direct measure is available. However, use of APLS formula "Weight $=($ age in years +4$) \times 2 "$ is widespread, and it seems to be helpful in sub-saharan pediatric population within an age range 1 to 10 years. Its performance is over $82,46 \%$ within an error of $10 \%$ from measured weight.

\section{Acknowledgments}

Professor Mamadou Troaré for support in the URFOSAME research laboratory.

\section{Conflicts of interest}

None.

\section{References}

1. Preedy Victor R. Handbook of anthropometry: Physical Measures of human Form in Health and Disease. Springer, USA. 2012;978:1-4419.

2. Wells M, Kramer E. Optimizing emergency drug dosing in children. Acad Emerg Med. 2008;15(12):1325.

3. The Advanced Life Support Committee of the Australian Resuscitation Council: Pediatric advanced life support - the Australian resuscitation council guidelines. MJA. 1996;165:199-206.

4. Abdel-Rahman SM, Ridge AL. An improved pediatric weight estimation strategy. Open Med Dev J. 2012;4:87-97.

5. Luscombe MD, Owens $\mathrm{BD}$, Burke $\mathrm{D}$. Weight estimation in pediatrics: a comparison of the APLS formula and the formula Weight $=3$ (age) +7. Emerg Med J. 2011;28 (7):590-593.

6. Anglemyer BL, Hernandez C, Brice JH, et al. The accuracy of visual estimation of body weight in the ED. Am J Emerg Med. 2004;22 (7):526-529.

7. Krieser D, Nguyen K, Kerr D, et al. Parental weight estimation is more accurate than other weight estimation methods for determining children's weight in an emergency department ?. Emerg Med J. 2007;24 (11):756-759.

8. Tinning K, Acworth J. Make your Best Guess: an updated method for pediatric weight estimation in emergencies. Emerg Med Australas. 2007;19(6):528-534.

9. Cattermole GN, Graham CA, Rainer TH. Pediatric weight estimate. Emerg Med J. 2012;29(1):82-83.

10. Seddon C, Lockitt L, Dhanjal S, et al. Validation of Advanced Pediatric Life Support Formulas for Weight Calculation in a Multiethnic Population. ISRN Pediatrics. 2012;2012:869634.

11. Dicko A, Alhousseini ML, Sidibé B, et al. Evaluation of the Mercy weight estimation method in Ouelessebougou, Mali. BMC Public Health. 2014;14:270.

12. Cattermole GN, Leung MPY, So HK, et al. Age-based formulae to estimate children's weight in the emergency department. Emerg Med J. 2011;28(5):390-339.

13. Advanced Life Support Group. Advanced pediatric life support: the practical approach. 5th ed. John Wiley \& Sons Ltd: Chichester, UK; 2011.

14. Marikar D, Varshneya K, Wahid A, et al. Just too many things to remember? A survey of pediatric trainees' recall of advanced pediatric life support (APLS) weight estimation formulae. Arch Dis Child. 2013;98 (11):921. 